\title{
9.5 Обгрунтування показників надійності промислових роботів і платформ у складі технологічного обладнання
}

Автоматизовані та робототехнічні комплекси дозволяють суттєво збільшити продуктивність праці, підвищити якість продукції, спростити переналагодження обладнання та забезпечити перехід до гнучких автоматизованих виробництв, найважливішою складовою яких $\epsilon$ промислові роботи-маніпулятори (ПР) та промислові платформи (ПП). Серед ПП найбільше поширення набули роботи-верстати на основі механізмів паралельної структури типу трипод і гексапод (рис. 1).

a)

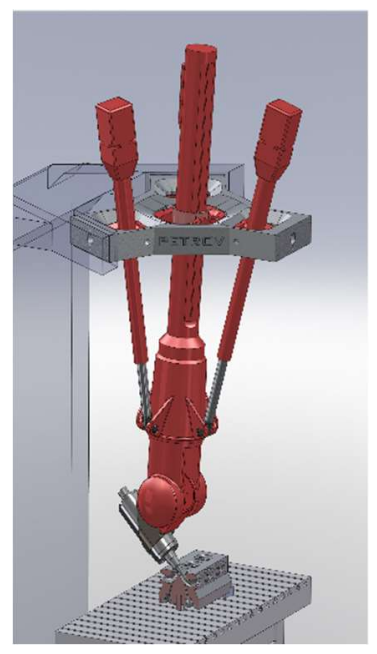

б)

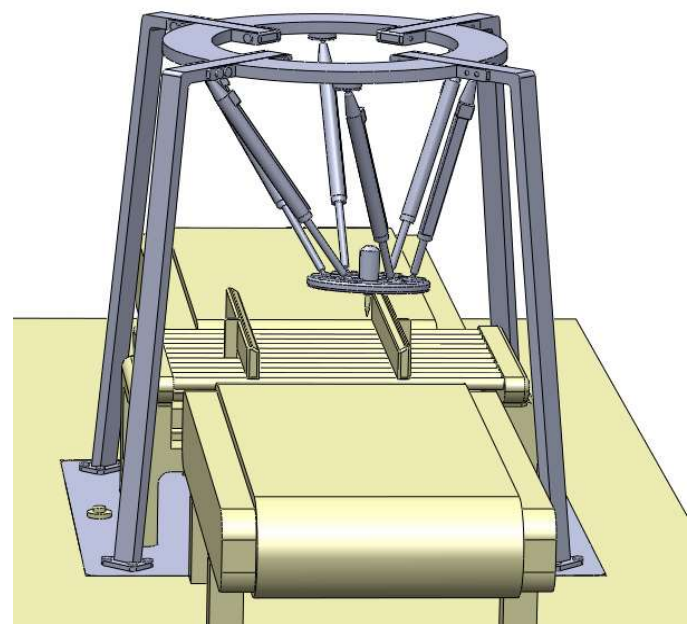

Рисунок 1. 3-Д моделі роботів-верстатів з механізмами паралельної структури типу (a) трипод і (б) гексапод

Відмови механізмів у складі ПР і ПП (у подальшому об'єкти, що підлягають розрахункам) у відповідності зі своєю фізичною природою можуть бути пов'язані з руйнуванням вузлів і деталей механізмів та їх приводів, заклинюванням окремих елементівта ін. причинами, які призводять до того, що технологічне обладнання не може виконувати своїх функцій. Такі відмови прийнято називати відмовами функиіонування (рис.2). 

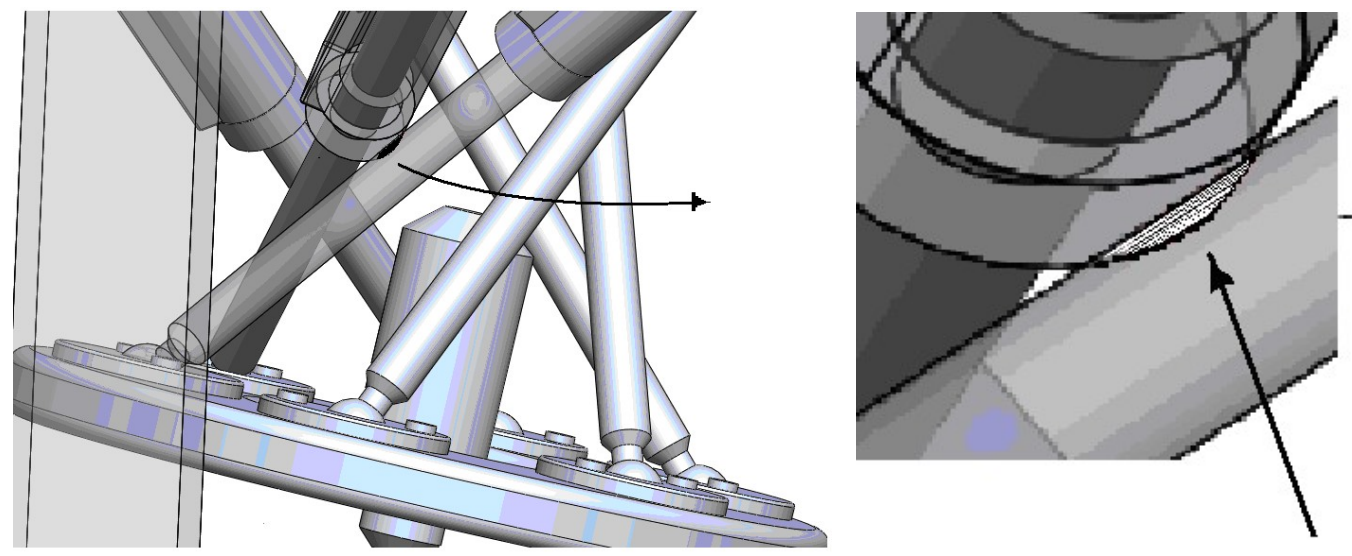

Рисунок 2. Моделювання явищ кінематичного запирання механізму гексапода

У випадках, коли роботоздатність об’єкту характеризується сукупністю значень деяких технічних параметрів, то ознакою виникнення відмови є вихід значень кожного із цих параметрів за межі допуску. Такі відмови називають параметричними. Наприклад, порушення точності обробки на верстаті-роботі, зменшення тиску в гідроприводах маніпуляторів та штангах гексаподу, тощо, звичайно не порушують подальше функціонування обладнання, однак воно стає нероботоздатним 3 погляду вимог, установлених нормативно-технічною документацією. Дуже часто параметричні відмови передують відмовам функціонування, а також можуть їх спричиняти. Роботизоване обладнання системної складності складається із багатьох елементів, які можуть бути відремонтовані або замінені. Поширений показник надійності - наробіток до відмови, тобто наробіток об'єкта від початку експлуатації до виникнення першої відмови. До показників безвідмовності й довговічності, що використовують при проектуванні об'єктів машинобудування, відносять кількісні характеристики, опрацьовані у статистичній теорії надійності. Ця теорія описує функціонування великої кількості об'єктів, які виготовляють та експлуатують у статистично однорідних умовах. На практиці прийнято застосовувати цю теорію також й до об'єктів, що випускають малими серіями, що характерно для сучасних конструкцій ПР і ПП. На стадії проектування показники безвідмовності й довговічності трактують як характеристики імовірнісних моделей створюваних об'єктів. На стадіях експериментальної досліджень, випробувань та експлуатації ці показники визначають як статистичні оцінки відповідних імовірнісних 
характеристик. Середній наробіток до відмови - математичне очікування наробітку об'єкта до першої відмови, можна визначити як функцію

$$
T_{f}=\int_{0}^{\infty} t f(t) d t=\int_{0}^{\infty} P(t) d t,
$$

де $t$ - сумарний наробіток; $P(t)$ - ймовірність бевідмовної роботи; $f(t)$ - щільність розподілення напрацювання до відмови.

Середній наробіток на відмову - відношення сумарного наробітку відновлюваного об'єкта до математичного очікування числа його відмов протягом цього наробітку. Цей показник звичайно використовується для відновлюваних об'єктів, при експлуатації яких проявляються багаторазово повторювані, як правило, несуттєві відмови, що не приводять до серйозних наслідків. Відповідна розрахункова залежність має вигляд

$$
T_{\mathrm{cp}}=t / M\{r(t)\},
$$

де $r(t)$ - число відмов, що настали протягом наробітку.

Коефіцієнт готовності характеризує готовність об'єкта до використання за призначенням у певний момент часу, крім запланованих періодів обслуговування, коли використання об'єкта за призначенням виключено. Цей показник є комплексним і кількісно об’єднує одночасно два важливих для технологічних систем показника - безвідмовність і ремонтопридатність:

$$
K_{\text {г }}=\frac{T\left(t_{0}\right)}{T\left(t_{0}\right)+T_{\text {в }}},
$$

де $T\left(t_{0}\right)$ - середнє напрацювання на відмову; $T_{\text {в }}$ середній час відновлення після відмови. Статистична оцінка коефіцієнта готовності

$$
\bar{K}_{\text {г }}=\frac{\bar{T}\left(t_{0}\right)}{\bar{T}\left(t_{0}\right)+\bar{T}_{\text {в }}} .
$$

Безпосереднє застосування законів розподілу наробітку до відмови або законів розподілу терміну служби дозволяє вирішувати завдання визначення показників надійності лише приблизно за низкою причин [583]: 
- по-перше, закон вибирається формально, за зовнішніми ознаками і часто не відображує процес формування відмови;

- по-друге, для одержання експериментальних даних, що дозволяють судити про закон розподілу, необхідні значний час і витрати.

Робота об'єкта, вихідний параметр якого має закон розподілу, що не залежить від часу, характеризується раптовими відмовами. У цьому випадку відповідно до експонентного закону надійності ймовірність безвідмовної роботи $P(T)=\exp (-\lambda t)$, де $\lambda-$ інтенсивність відмов. Звичайно в цьому випадку параметри стану вважають випадковими величинами й безвідмовність може оцінюватися згідно незалежній від часу ймовірності знаходження вихідного параметра в допустимих границях $P_{\mathrm{p}}$ (квазістатична постановка [583]).

Тоді при статичних границях $P_{\mathrm{p}}=P\left\{R_{1}<z<R_{2}\right\}=\int_{R_{1}}^{R_{2}} \varphi(z) d z$,

при випадковій границі $\quad P_{\mathrm{p}}=P\{\xi>0\}=\int_{0}^{\infty} \psi(\xi) d \xi$.

Встановити зв'язок між характеристиками $P(T)$ і $P_{\mathrm{p}}$ при раптових відмовах можна, якщо розглядати параметр стану $z$ як випадкову послідовність, спостережувану у фіксованих точках тимчасового інтервалу. Отримано

$$
P(T)=\exp \left[-\left(1-P_{p} n T\right)\right]
$$

де $n$ - середнє число фіксованих точок за одиницю часу.

У загальному випадку роботоздатність ПР i ПП та якість їх функціонування визначається не одним, а сукупністю $S$ вихідних параметрів стану $z_{1}, z_{2} \ldots z_{S}$, які можна вважати компонентами деякого вектора Z. Простір станів можна розділити деякою граничною поверхнею на дві області: область роботоздатних станів і область відмов. Безвідмовність у цьому випадку визначається як імовірність того, що за час $T$ функціонування системи параметри стану $z_{i}$ не виходять за відповідні границі $R_{i 1}$ i $R_{i 2}$ :

$$
P(T)=P\{Z \in \Omega / t \leq T\}=P\left\{R_{11}<z_{1}<R_{12}<z_{2}<R_{22} \ldots<R_{S 1}<z_{S}<R_{S 2} / t \leq T\right\} .
$$

Перетинання вектором $Z$ у якийсь момент часу поверхні граничних станів 
означає відмову. Визначальними у характеристиці процесів, що призводять до відмови об'єкта, є швидкість їх протікання [584]. Процеси, що протікають із високою швидкістю (період зміни порядку долі секунди), закінчуються протягом циклу роботи машини й знову виникають при наступному циклі. Для оцінки усередненого параметра потоку відмов $\mu$ необхідно знати щільність спільного розподілу параметра стану $z(t)$ і швидкості його зміни в часі $\dot{z}(t)$. У багатьох випадках такі процеси описуються стаціонарною випадковою функцією 3 нормальним законом розподілу як самого параметра стану $z$, так і швидкості його зміни $\dot{z}$. Тоді відповідно до формули Райса усереднений параметр потоку відмов визначають так

$$
\bar{\mu}=\frac{1}{2 \pi} \frac{\sigma_{\dot{z}}}{\sigma_{z}} \exp \left[-\frac{\left(R-m_{z}\right)^{2}}{2 \sigma_{z}^{2}}\right],
$$

де $\sigma_{z} \mathrm{i} \sigma_{\dot{z}}$-середньоквадратичні значення відповідно $z \mathrm{i} \dot{z} ; R$-границя.

Безвідмовність, як імовірність відсутності за час наробітку $T$ першої параметричної відмови, визначать так

$$
P(T)=\exp \left\{-\frac{T}{2 \pi} \frac{\sigma_{\dot{z}}}{\sigma_{z}} \exp \left[-\frac{\left(R-m_{z}\right)^{2}}{2 \sigma_{z}^{2}}\right]\right\} .
$$

Процеси, що протікають із середньою швидкістю, відбуваються під час безперервної роботи ПР і ПП й виміряються хвилинами й годинами. Це, у першу чергу, стосується зміни умов навантаженності, температури тощо. Якщо розсіювання режимів навантаженності таке, що при несприятливій комбінації показників режимів параметр стану об'єкта може вийти за допустимі границі, то при функціонуванні ПР і ПП можливі раптові відмови, імовірність появи яких повністю визначається ймовірністю несприятливої ситуації. Дослідження надійності в цьому випадку розпадається на три основні етапи:

- побудова на основі теоретичних або експериментальних досліджень залежності вихідного параметра від показників навантаженності;

- ретельний статистичний аналіз умов експлуатації, імовірнісний опис показників навантаженності; 
- побудова розподілу вихідного параметра.

Розподіл вихідного параметра є достатнім, щоб за формулами (5), (6) і (7) визначити оцінки надійності $P_{\mathrm{p}}$ і $R(T)$.

Процеси, що протікають із низькою швидкістю, мають місце у період роботи роботизованого обладнання між періодичними оглядами чи ремонтами. До них відносяться зношування, накопичення утомних пошкоджень, корозія тощо. Такі процеси викликають зміну статистичних характеристик параметра стану у часі, у зв'язку із чим його вже не можна розглядати як стаціонарну випадкову функція. Процеси такого типу звичайно призводять до поступових відмов. При цьому зношування, як основний чинник, може викликати граничні стани різного роду. При досягненні величини зносу деякого граничного значення можуть відбуватися різкі, стрибкоподібні зміни в результаті кінематичних взаємодій функціонування ПР і ПП, що призводять до відмов. В інших випадках вихідний параметр механічної системи, що залежить від ступеня зносу кінематичних пар, не має екстремальних зон і монотонно погіршується в процесі експлуатації. При досягненні параметром стану значень, регламентованих технічною документацією, наступає параметрична відмова, найбільш проста модель якої базується на припущенні лінійної залежності вихідного параметра від величини зносу. На практиці нерідкі випадки, коли поступові відмови внаслідок зношування й раптові відмови, викликані в основному несприятливою комбінацією умов навантаженності, практично між

собою не зв'язані. Імовірність безвідмовної роботи при спільній дії цих різних:

$$
P(T)=P_{3 \mathrm{H}}(t) \cdot P_{\mathrm{p}}(T),
$$

де $P_{\text {зн }}(t)$ і $P_{\mathrm{p}}(T)$ - ймовірності безвідмовності, зумовлені відповідно зношуванням і раптовими відмовами.

Якщо можливо розчленувати складну систему на окремі елементи і для кожного них окремо визначити ймовірність безвідмовної роботи, то для розрахунків показників надійності системи використовують структурні моделі (схеми). Найбільш характерний випадок, коли відмова кожного 3 елементів виводить із ладу всю систему - це послідовне з'єднання елементів. Приклад 
застосування - зубчасті колеса, вали, підшипники як елементи механічної трансмісії у складі ПР. Відмова кожного з таких елементів призводить до відмови усієї системи. Імовірність безвідмовної роботи такої системи дорівнює добутку ймовірностей безвідмовної роботи елементів

$$
P(T)=P_{1}(t) \cdot P_{1}(t) \ldots P_{n}(t)=\prod_{i=1}^{n} P_{i}(t) .
$$

Якщо вихід 3 ладу всіх означених елементів спричинений тільки раптовими відмовами, які підкоряються експонентному закону, тобто

$$
P_{1}(t)=\exp \left(-\lambda_{1} t\right) ; P_{2}(t)=\exp \left(-\lambda_{2} t\right) ; \ldots P_{n}(t)=\exp \left(-\lambda_{n} t\right),
$$

то для такої системи ймовірність безвідмовної роботи визначають так

$$
P(t)=\prod_{i=1}^{n} \exp \left(-\lambda_{i} t\right)=\exp \left[-\left(\lambda_{1}+\lambda_{2}+\ldots+\lambda_{n}\right) t\right] .
$$

Таким чином, імовірність безвідмовної роботи складної системи, що складається з елементів, підвержених раптовим відмовам, також підкоряється експонентному закону з параметром $\lambda=\sum_{i=1}^{n} \lambda_{i}$. Простота розрахунків показників надійності системи при раптових відмовах елементів за рівнянням (14) на практиці іноді призводить до того, що цією формулою користуються також і у випадках, коли причина виходу з ладу - поступові відмови. Це неприпустимо, оскільки у таких випадках є обов'язковим використання загальної формули (11).

У сучасному машинобудуванні поширене загальне резервування обладнання, зокрема, у всіх відповідальних вузлах механізмів і приводів ПР і ПП застосовують дублюючі системи мащення, ущільнення тощо.

Якщо у структурній моделі надійності обєкту $n_{1}$ елементів не дубльовані, а $n_{2}$ елементів дубльовані, то ймовірність безвідмовної роботи такої системи

$$
P(t)=P_{d}(t) \cdot P_{c}(t)=\prod_{i=1}^{n_{1}} P_{i}(t) \cdot \prod_{i=1}^{n_{2}}\left[1-Q_{j}^{2}(t)\right] .
$$

Для можливості практичного застосування у розрахунках показників надійності на різних рівнях моделювання опрацьовано відповідну універсальну комп'ютерну модель, у якій основними відмовами $\epsilon$ раптові, однак їх 
інтенсивність залежить від процесів, що повільно протікають, наприклад, від процесів зношування (рис. 3). Розроблений алгоритм розрахунків показників надійності системи, вихідний параметр якої представлений у вигляді випадкової послідовності, імітує роботу $N$ зразків кінематичної пари ПР чи ПП у реальних експлуатаційних умовах аж до їх повного зносу [584].

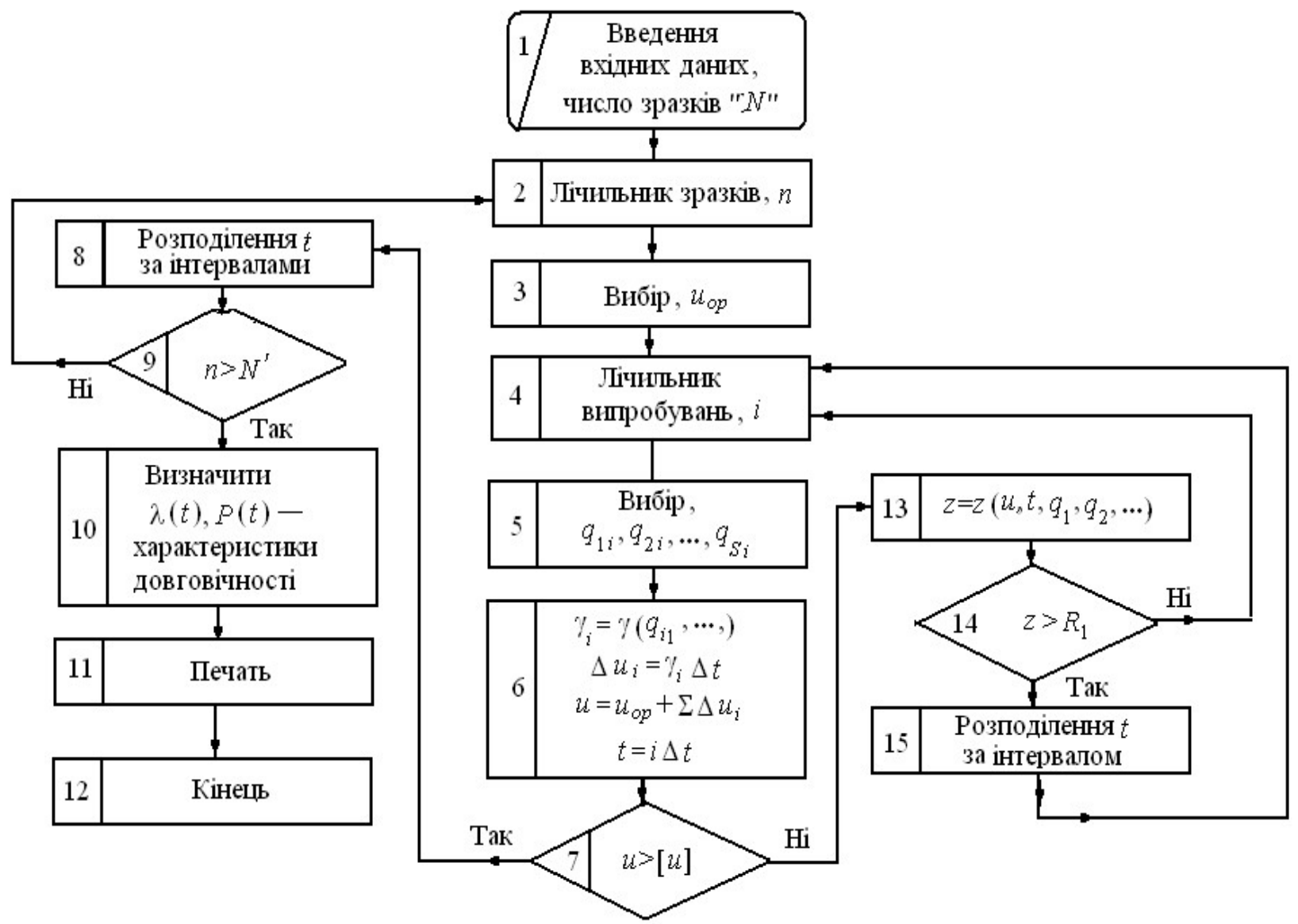

Рисунок 3. Структурна схема алгоритму розрахунку надійності об’єкта при раптових відмовах з урахуванням зносу

Для кожного зразка за методом Монте-Карло, відповідно до відомих розподілів технологічних параметрів, визначають початковий базовий розмір $u_{0}$ i критеріальний параметр $a_{0}$ (наприклад, твердість), що визначає середню швидкість зношування (оператор 3). Зразок піддають «випробуванням», для кожного з яких за методом Монте-Карло розігрують значення показників навантаженності $q_{1}, q_{2}, \ldots, q_{S}$ (оператор 5), та за прийнятою математичною моделлю швидкості зношування $V_{3 н}\left(q_{1}, q_{2}, \ldots, q_{S}\right)$ оцінюють (оператор 6)

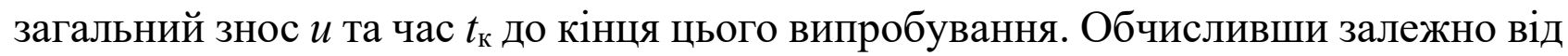


$u, t_{\mathrm{\kappa}}$ i характеристик навантаженності вихідний параметр об'єкта $z$ (оператор 13), встановлюють (оператор 14) наявність раптової параметричної відмови. У випадку відмови до інтервалу, що відповідає часу його появи, додається одиниця (оператор 15). «Випробування» проводяться доти, поки знос зразка не перевищить допустимого значення (поступова відмова). Потім переходять до «випробувань» наступного зразка. Розподіл моментів параметричних відмов за часовими інтервалами дозволяє визначити для кожного інтервала інтенсивність відмов $\lambda(t)$ з наступною оцінкою ймовірності безвідмовної роботи $P(t)$ (оператор 10). Запропонована модель дозволяє вирішувати практичні задачі з порівняння різних варіантів конструкцій кінематичних пар ПР і ПП, обгрунтовувати раціональний розподіл навантаження та норм надійності між елементами механічних систем, приводів тощо.

За припущенням, що елементи системи виходять з ладу незалежно один від одного, і відмова кожного елемента призводить до відмови усієї системи, виконується нерівність

$$
P_{1}(t) \cdot P_{2}(t) \cdots P_{n}(t) \geq P^{\mathrm{tp}}
$$

де $P^{\text {тр }}$ - задана при проектуванні надійність системи.

Для оптимізації рівня надійності підсистеми гідроприводу гексаподу використано метод раціонального розподілу надійності елементів [584]. Так, ля системи, що має $n$ елементів надійності, розташуємо показники надійності у порядку зростання $P_{1} \leq P_{2} \leq \ldots \leq P_{n}$. Кожен із показників $P_{1}, P_{2}, \cdots, P_{k}$ збільшують до одного і того ж значення $P_{0}^{T P}$, а починаючи 3 $P_{k+1}, \cdots, P_{n}-$ не змінюють. Номер $k$ вибирають за максимальним значенням $j$, для якого виконуються умови

$$
P_{j} \leq\left(P^{\mathrm{Tp}} / \prod_{j=1}^{n+1} P_{j}\right)^{\frac{1}{j}}=r_{j}, P_{0}^{\mathrm{Tp}} \leq\left(P^{\mathrm{Tp}} / \prod_{j=1}^{n+1} P_{j}\right)^{\frac{1}{k}},
$$

де $P_{n+1}=1$ приймається за визначенням. 
Очевидно, що надійність системи після знаходження $P_{0}^{\text {тр }}$ задовольняє умовам (16), оскільки нове значення показника $P^{\mathrm{Tp}}$ дорівнює

$$
\left(P_{0}^{\mathrm{Tp}}\right)^{k} \cdot P_{k+1} \cdots P_{n}=P^{\mathrm{Tp}} .
$$

Для гексаподу, що має шість паралельних механізмів поступального руху штанг, вирізнено три підсистеми (1 - гідропривода, 2 - шарнірні опори штанг, 3 - вузла шпинделя) і визначено необхідність дотримання умови

$$
P_{\Gamma}^{6} \cdot P_{\mathrm{c}}^{12} \cdot P_{\amalg} \geq P^{\mathrm{Tp}},
$$

де $P_{\text {г }}$ - показник надійності кожного з шести незалежних модулів підсистеми гідроприводу; $P_{\mathrm{c}}$ - показник надійності кожного $з$ дванадцяти сферичних шарнірів підсистеми опор; $P_{ш}$ - показник надійності електромеханічного приводу підсистеми вузла шпинделя.

Виходячи із статистичних значень: $P_{\mathrm{r}}=0,97 ; P_{\mathrm{c}}=0,99 ; P_{\mathrm{m}}=0,95$, отримано

$$
P=P_{\mathrm{\Gamma}}^{6} \cdot P_{\mathrm{c}}^{12} \cdot P_{\mathrm{\amalg}}=0,97^{6} \cdot 0,99^{12} \cdot 0,95=0,83 \cdot 0,89 \cdot 0,95=0,71 .
$$

Для гексапода з підсистемою привода поступального руху штанг при $P_{\text {к }}$ $=0,96$ отримано: $P=P_{k}^{2} \cdot P_{\ddot{o}}^{3} \cdot P_{\sigma}=0,96^{2} \cdot 0.99^{3} \cdot 0,95=0,84$

3 метою визначення найбільш ефективних напрямів підвищення проектного значення показника надійності гексапода до рівня $P^{\text {тр }}=0,84$ визначено раціональний розподіл значень показників надійності підсистем. Спочатку припущено, що $k=1$, тоді за формулою (16) отримано

$$
P_{0}^{\mathrm{Tp}}=\left(\frac{0,84}{0,89 \cdot 0,95 \cdot 1,0}\right)^{\frac{1}{1}}=0,999 .
$$

В результаті отримано $P=0,999 \cdot 0,89 \cdot 0,95=0,84$, але такий розподіл показників надійності підсистем не є раціональним, оскільки для підсистеми 1 , що складається з шести незалежних модулів поступального руху, уявляється практично неможливим і економічно недоцільним подальше підвищення 
показника з $P_{\text {г }}=0,97$ до $P_{\Gamma}=\sqrt[6]{0,999}=0,9999999$. Із формули (16) визначено раціональний розподіл показників надійності для підсистем

$$
r_{1}=\left(\frac{0,84}{0,89 \cdot 0,95 \cdot 1,0}\right)^{\frac{1}{1}}=0,999 ; r_{2}=\left(\frac{0,84}{0,95 \cdot 1}\right)^{\frac{1}{2}}=0,88 ; r_{3}=\left(\frac{0,84}{1}\right)^{\frac{1}{3}}=0,94 \text {. }
$$

В результаті отримано $P_{1}<r_{1}, P_{2}<r_{2}, P_{3}>r_{3}$, у цьому разі найбільше значення $j$ за умови $P<r$ дорівнює $j=2$, отже прийнято $k=2$ i визначено $P_{0}^{\mathrm{Tp}}=\left(\frac{0,84}{0,95 \cdot 1,0}\right)^{\frac{1}{2}}=0,88$. Це означає, що показники надійності для підсистем $1 \mathrm{i}$ 2 необхідно підвищити відповідно з 0,83 до 0,88 і з 0,89 до 0,94. Для підсистеми 3 показник надійності можна залишити на попередньому рівні. В результаті раціонального розподілу показників надійності для трьох підсистем гексаподу і системи в цілому отримано $P_{\Gamma}=\sqrt[6]{0,88}=0,98 ; P_{\mathrm{c}}=\sqrt[12]{0,94}=0,995 ; P_{\mathrm{\amalg}}=0,95$ і $P=P_{\Gamma}^{6} \cdot P_{\mathrm{c}}^{12} \cdot P_{\mathrm{W}}=0,98^{6} \cdot 0,995^{12} \cdot 0,95=0,88 \cdot 0,94 \cdot 0,95=0,84$, тобто витримано проектні вимоги щодо надійності механізму гексаподу.

Опрацьовано алгоритм структурного аналізу надійності механізмів ПП, розроблено практичні рекомендації, щодо оптимального розподілу норм надійності між підсистемами гексаподу на етапі проектування. 